\title{
PATTERNS AND PROCESSES OF DIVERSIFICATION: SPECIATION AND HISTORICAL CONGRUENCE IN SOME NEOTROPICAL BIRDS
}

\author{
JoEl CRACRAFT \\ Department of Anatomy, University of Illinois, P.O. Box 6998, Chicago, IL 60680 and \\ Department of Zoology, Field Museum of Natural History, Chicago, IL 60605 \\ AND \\ Richard O. PRUM \\ Museum of Zoology, and Department of Biology, University of Michigan, \\ Ann Arbor, MI 48109
}

\begin{abstract}
This paper documents congruence in geographical patterns of speciation for four clades of birds having taxa endemic to the same areas within the Neotropics. Two genera, Pionopsitta parrots and Selenidera toucans, corroborate a well known biogeographic disjunction in which taxa endemic to southern Central America and the Chocó region of northwestern South America are the sister-group to a radiation within the Amazon basin. These two genera, along with two lineages within the toucan genus Pteroglossus, also document a pattern of historical interrelationships for four well known areas of endemism within Amazonia: Guyanan + (Belém-Pará + (Inambari + Napo)).

These generalized historical patterns are interpreted to have arisen via fragmentation (vicariance) of a widespread ancestral biota. A review of the paleogeographic evidence suggests that these vicariance events could have originated as a result of several different mechanisms operating at various times during the Cenozoic. The inference that diversification of the Neotropical biota is primarily the result of the most recent of these possible vicariance events, namely isolation within Quaternary forest refugia, is unwarranted, given present data. These patterns of historical congruence are also interpreted as direct evidence against the hypothesis that diversification of the forest biota was a consequence of parapatric differentiation along recently established ecological gradients.
\end{abstract}

Received December 22, 1986. Accepted January 11, 1988

The origin and evolution of biotic diversity remains a central problem within evolutionary biology. The hypothesis that speciation is predominately allopatric has been highly corroborated over the past 50 years (evidence summarized in Mayr [1942, 1963]; Bush, 1975; Futuyma and Mayer, 1980 ), thus it is generally agreed that biotic diversity is the result of episodes of differentiation within spatially isolated populations, accumulated over time. Allopatric differentiation is now postulated to develop in two ways - by vicariance of widespread ancestral populations following the inception of a physiographic or ecological barrier (type Ia of Bush [1975]; dichopatric of Cracraft [1984]), or by long-distance dispersal across a preexisting barrier (peripatric speciation of Mayr [1982a]). Some workers (Mayr, 1963 p. 513, 1982a, 1982b; Bush, 1975) have postulated that peripatric speciation is the more common of the two modes. Yet, if we are to understand processes of faunal assembly within continental biotas, it will first be necessary to document the historical patterns of speciation within the component clades of those biotas. By searching for congruence in the historical patterns of differentiation, we can evaluate the relative contributions that dichopatric (vicariant) and peripatric modes of speciation have made to the evolution of diversity within continental biotas (Rosen, 1978; Cracraft, 1982, 1983a, 1983b, 1986; Wiley, 1981; Wiley and Mayden, 1985).

Systematic and biogeographic analyses of the Neotropical biota in general and of birds in particular have played a central role in our current models of biotic diversification (Haffer, 1969, 1974, 1982, 1985; Simpson and Haffer, 1978; Vuilleumier, 1971). At this time, the refuge hypothesis (Haffer, 1969; Simpson and Haffer, 1978; Prance, $1982 a$ ) is the most widely accepted model for the evolution of the Neotropical biota. According to this model, speciation patterns of Neotropical faunal elements arose as a result of cyclical expansion and contraction of the forest and nonforest habitats during Quaternary climatic fluctuations (Haffer, 1969, 1970a, 1974, 1977, 1979, $1981,1982,1985)$. 
Patterns of endemism (Müller, 1973; Haffer, 1974, 1978; Cracraft, 1985) and geographic variation (Haffer, 1970a, 1974; Haffer and Fitzpatrick, 1985) have been established for many groups of Neotropical birds. Despite this information, we suffer from an almost complete lack of understanding about the phylogenetic patterns of avian differentiation within the Neotropics or about the existence of spatial and temporal congruence in those patterns. The purpose of this paper is to present evidence for one such pattern of historical biogeographic congruence within the Neotropical biota based on phylogenetic hypotheses for four clades of birds.

\section{MATERIALS AND METHODS Evolutionary Taxa}

This study examines spatial patterns of cladogenesis using discrete evolutionary taxonomic units or "phylogenetic species" (Nelson and Platnick, 1981; Cracraft, 1982, $1983 a, 1986,1987)$. These taxa may be diagnosed in terms of unique combinations of discrete characters, and they cannot be further subdivided on the basis of diagnostic character variation into smaller units (i.e., these taxa are basal). Many basal taxa within birds have been united into a variable number of "biological species," either because it is presumed that the forms have not differentiated sufficiently to be reproductively isolated or because some specimens within zones of sympatry are considered to be hybrids. As is well known, however, patterns of reproductive cohesion and disjunction among populations do not necessarily parallel phylogenetic patterns of differentiation (Cronquist, 1978; Rosen, 1978; Cracraft, 1983a, 1987). Hence, phylogenetic, not "biological," species must be used to reconstruct the spatial history of differentiation. Both species concepts will provide the same pattern only when all included "biological species" are monotypic taxa.

Because we employ basal taxa that are defined in terms of discrete character variation, we will not be concerned with nondiscrete (continuous) variation such as that found along clines. This type of variation, although critical for examining the population-level dynamics of differentiation, cannot be used to delimit taxa or to for- mulate genealogical hypotheses. A major problem facing evolutionary biologists is whether observed discrete taxa arose sympatrically, parapatrically, or allopatrically. The analysis of historical pattern is critical for evaluating the potential influence of these different modes (Wiley, 1981; Cracraft, 1982), and the use of discrete basal taxa does not prejudge what those patterns might be or how they might be interpreted (the evolutionary significance of clinal variation, for example whether it is the result of primary or secondary intergradation, is in part dependent upon a correct resolution of historical pattern). Complete understanding of patterns and processes of diversification within any biota will require analyses of both discrete and nondiscrete variation, but identification of postulated patterns of vicariance and evaluation of their significance necessitates analysis of diagnostically discrete taxa.

\section{Phylogenetic Analysis}

Phylogenetic hypotheses were generated by cladistic analysis (Eldredge and Cracraft, 1980; Wiley, 1981; Nelson and Platnick, 1981), using the numerical cladistic program, Phylogenetic Analysis using Parsimony (PAUP) of D. L. Swofford (1985). Character variation was studied using specimens housed in the American Museum of Natural History (New York), Field Museum of Natural History (Chicago), Museum of Comparative Zoology (Cambridge, MA), and the University of Michigan Museum of Zoology (Ann Arbor), and external morphological characters were coded binarily into primitive-derived character-states using outgroup comparison (see above references and Maddison et al. [1984]). In all cases, outgroup taxa were easily identified and included species in closely related species-groups or genera (see Results).

In order to examine the preliminary hypothesis of ingroup monophyly and to evaluate alternative interpretations of polarity, minimum-length trees were generated using the unordered character option of PAUP. This option permits all possible characterstate transformations and thus does not make a prior judgment about character polarity. The results presented below, however, were produced using the ordered char- 
acter-state option based on the hypothesized polarity sequences. PAUP generates unrooted networks, and these trees were rooted by specifying an outgroup taxon as that root.

\section{RESULTS}

\section{Patterns of Differentiation}

The four clades discussed in this section were chosen because they exemplify congruence in their spatial pattern of differentiation. Each clade consists of three or more nonsympatric, basal taxa distributed within established areas of endemism (Haffer, 1974; Cracraft, 1985), and together they produce four independent area-cladograms for the historical interrelationships of these areas. We have undertaken analyses of other groups, and congruent patterns different from the results presented here have been discovered (Prum, 1982, 1988; Cracraft, unpubl.); these other patterns will be described elsewhere. Theoretically, conflicting general patterns such as these are to be expected, inasmuch as all continental biotas have had a long complex history, with paleogeographic and paleoclimatic events having influenced spatial patterns of differentiation differently among groups. The key to unraveling this complexity, we suggest, is to delineate these different congruent patterns and then seek to resolve any conflicts among them by recourse to still more general explanatory hypotheses.

Pionopsitta. - The parrot genus Pionopsitta (Psittacidae) consists of eight (possibly nine) evolutionary taxa distributed allopatrically in Central and South America (Fig. 1). Haffer (1970a pp. 290-295) discussed the distributional patterns of the forms of the Amazon basin, northwest South America, and Central America. He recognized six species but did not treat another species included here, $P$. pileata. Forshaw and Cooper (1973 pp. 487-494) accepted six species in the genus, but placed $P$. vulturina in its own genus, Gypopsitta, based on numerous derived characters. Differences in species limits between these two studies and the phylogenetic species of this analysis are relatively minor. Both Haffer (1970a) and Forshaw and Cooper (1973) combined $P$. haematotis and $P$. coccinicollaris into a single biological species, but we recognize them as phylogenetically differentiated taxa. Two subspecies of $P$. barrabandi have been recognized by previous workers. The form distributed south of the Amazon, aurantiigena, was described by Gyldenstolpe (1951 pp. 67-68) as having bright orange on the cheeks, bend of the wing, and thighs, compared to the more yellowish or yellow-orange color of nominate barrabandi. We have been unable to confirm this distinction, because critical specimens are few in number and appear to show some gradation in color (specimens in the Louisiana State University Museum of Zoology also suggest that these two forms may not be distinct; J. V. Remsen, pers. comm.). We plot the distributions of both forms in Figure 1 but recognize one species in the systematic analysis. A close relative, Hapalopsittaca melanotis, was used as a root for the tree and, along with other South American parrots, as an outgroup in the character analysis (Hapalopsittaca and Pionopsitta are united by having a green tail, tipped with dark blue).

Phylogenetic analysis using 26 characters (Table 1) revealed a single most parsimonious tree (29 steps, consistency index of 0.897; Fig. 1). The genus is divisible into two basal lineages: $P$. pileata of the Serra do Mar center of endemism in southeastern coastal Brazil is the sister-species of all the remaining species. This latter clade exhibits a cis-trans-Andean pattern of relationships. Thus, one lineage shows a Chocó-Central American (trans-Andean) distribution: $P$. haematotis, distributed from western Panama north to southern Mexico, is the sisterspecies of $P$. coccinicollaris of eastern Panama and northwestern Colombia (western part of the Nechí center of endemism); these two taxa are, in turn, the sister-group of $P$. pulchra of the Chocó. This lineage is the sister-group of a larger species-group distributed in the Amazon basin (cis-Andean). Within this latter clade, $P$. caica of the Guyanan center of endemism is the sister-taxon of three well-defined species: $P$. pyrilia of northwestern Colombia from Lake Maracaibo to the northern part of the Chocó, and its sister-pair, $P$. vulturina of the Pará and Belém (Maranhão) centers of endemism and $P$. barrabandi of the Napo (nominate barrabandi) and Inambari (aurantiigena) centers. 

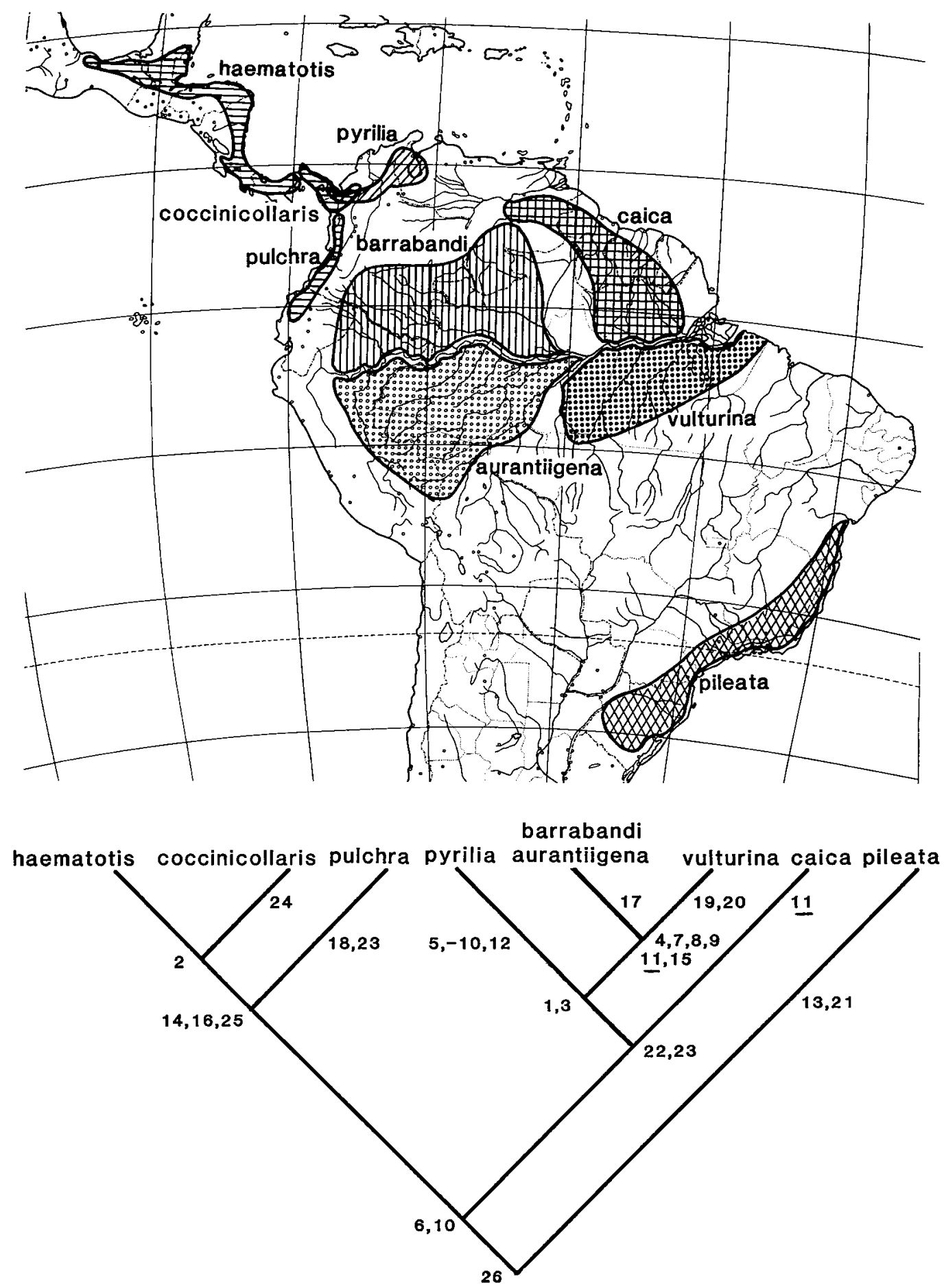

Fig. 1. Distributions and a phylogenetic hypothesis for the differentiated taxa of the genus Pionopsitta. A tree of 29 steps (consistency index $=0.897$ ) was produced based on an analysis of 26 ordered characters (Table 1). Distributions are from Haffer (1970a fig. 4) and Forshaw and Cooper (1973). Parallelisms are indicated by underlining, and reversals are indicated by negative numbers. 


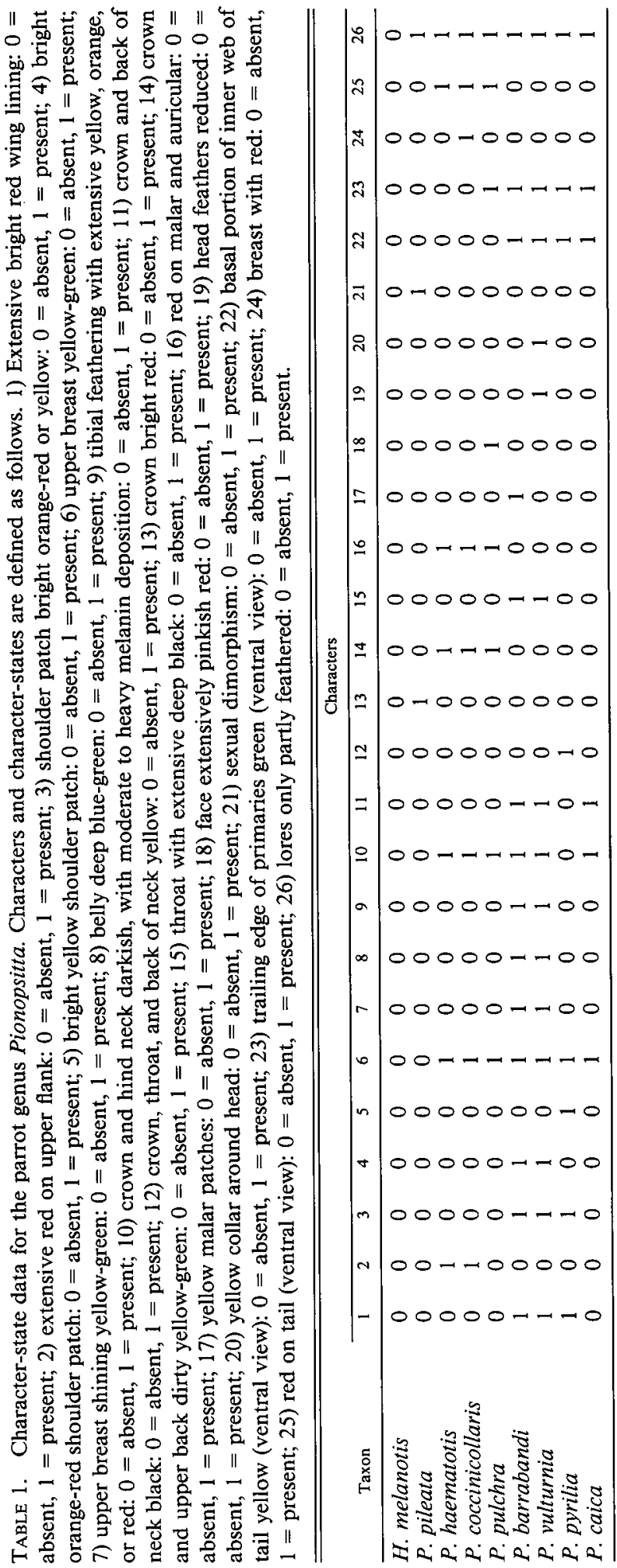



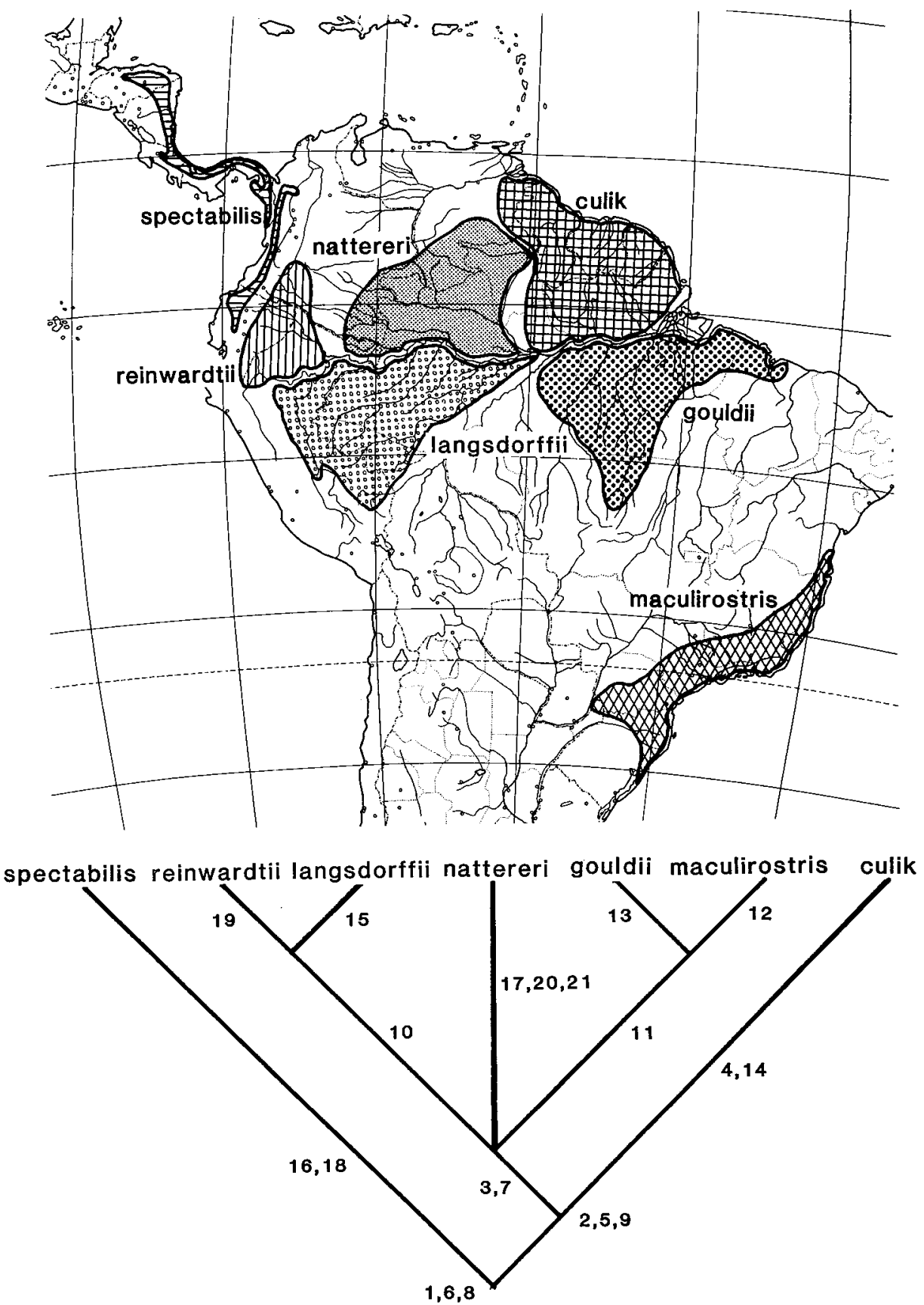

FIG. 2. Distributions and a phylogenetic hypothesis for the differentiated taxa of the genus Selenidera. Species in the genus Andigena were used as an outgroup and root for the tree. A tree of 21 steps (consistency index $=$ 1.00) was produced using 21 ordered characters (Table 2). Distributions are after Haffer (1974 fig. 16.22 and p. 240).

The relationships shown in Figure 1 are strongly supported by the data of Table 1 , with only one case of parallelism (character 11) and one reversal (character 10). Haffer
(1985 pp. 134-135) proposed that $P$. caica is most closely related to $P$. vulturina and that they are, in turn, the sister-group of $P$. barrabandi. He presented no evidence to 


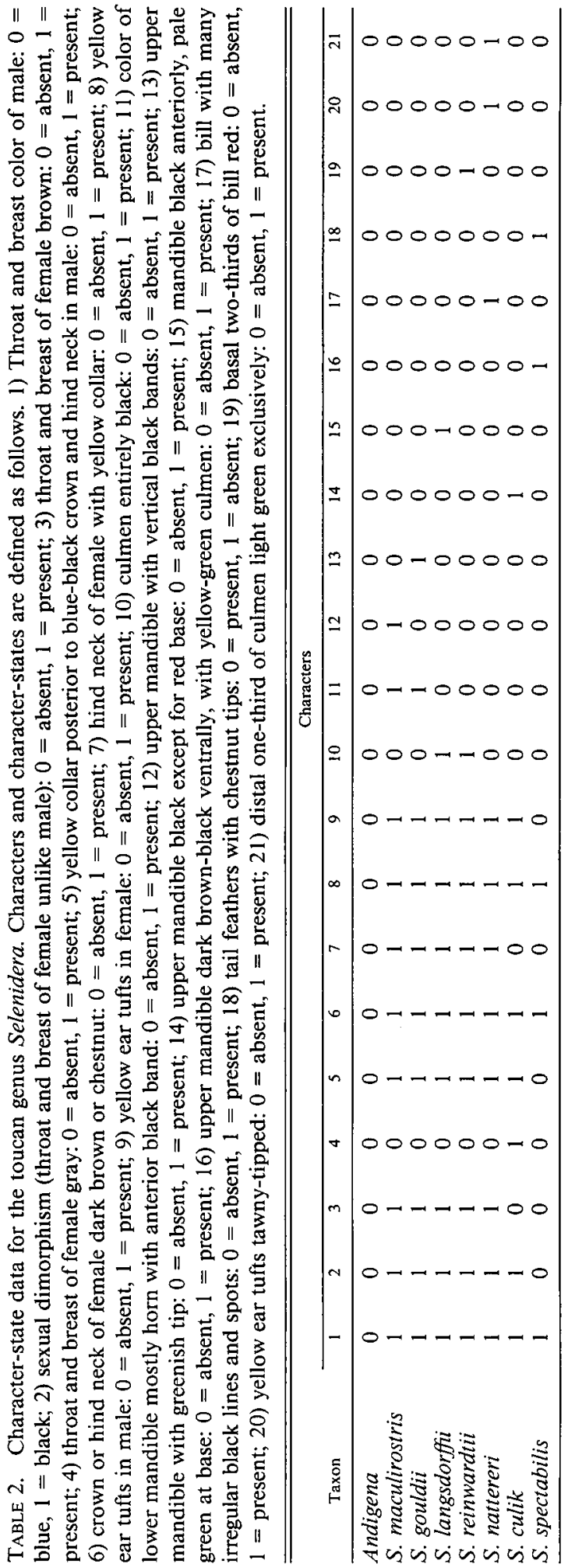


support this hypothesis, however, and the data presented in Table 1 and Figure 1 do not corroborate those relationships.

Selenidera. - Toucans of the genus Selenidera (Ramphastidae) include seven differentiated taxa distributed in Amazonia, southeastern Brazil, northwestern Colombia, and Central America (Fig. 2). Haffer (1974) presented detailed distributional and systematic data. Although Haffer (1974 p. 189) proposed a general phylogenetic hypothesis for the species in the Ramphastidae, it was not supported by character-state data and differs significantly from those postulated here for Selenidera and two clades within Pteroglossus (Prum, 1982, unpubl.). Within Selenidera, character polarity was hypothesized based on outgroup comparison to its probable sister-group, the genus Andigena, and to other toucans (Prum, 1982, unpubl.).

The hypothesis diagramed in Figure 2 represents the most parsimonious tree for the 21 characters of Table 2 (because of the trichotomy, three dichotomous trees are possible). The tree has a length of 21 steps and a consistency index of 1.00 , thus indicating no homoplasy in the data. This phylogenetic hypothesis for Selenidera displays a primary cis-trans-Andean distribution. Selenidera spectabilis of the Choco and Central America is the sister-species of the entire Amazonian radiation. Within this Amazonian clade, $S$. culik of the Guyanan area of endemism is the sister-species of the five remaining Amazonian taxa. Selenidera maculirostris of the Serra do Mar center in southeastern coastal Brazil and $S$. gouldii of the Pará and Belém centers form a clade. Among the west Amazonian forms, S. reinwardtii of the Napo area and S. langsdorffii of the Inambari center are sister-species. These two phylogenetic species are known to hybridize in Peru and are sometimes placed in a single biological species (Haffer, 1974 p. 241). The relationships of $S$. nattereri are unresolved by this data set, and consequently a trichotomy is recognized in Figure 2.

With the exception of $S$. nattereri, the relationships of these species (Fig. 2) are well supported by the available evidence (Table 2). Haffer (1974 p. 189) suggested a very different genealogical arrangement, with the genus being divisible into two lineages: culik + (gouldii + maculirostris) and nattereri + (reinwardtii + spectabilis). Our analysis indicates that character data for external morphological features are inconsistent with that hypothesis.

Pteroglossus. - The genus Pteroglossus (Ramphastidae) contains approximately 30 differentiated taxonomic units distributed over much of tropical America (Haffer, 1974). We will discuss here two monophyletic species-groups having patterns of endemism within the Amazon basin; the phylogenetic relationships of the entire genus will be considered elsewhere (Prum, unpubl.). The distributions of the two speciesgroups are shown in Figures 3 and 4, along with phylogenetic hypotheses depicting their relationships. For each analysis, outgroup taxa included other Pteroglossus species-groups (Haffer, 1974; Prum, 1982), the genus Ballonius (which is the apparent sister-group of Pteroglossus [Prum, 1982, unpubl.]), and all other toucans.

Based on the character-state data shown in Table 3, a single most parsimonious tree (nine steps, consistency index $=1.00$ ) was found for the $P$. viridis species-group (Fig. 3). One species, $P$. viridis, is endemic to the Guyanan center but also ranges westward into the eastern portion of the Pantepui center. The sister-group of $P$. viridis consists of two differentiated taxa, $P$. inscriptus of the Belém, Pará, and Rondônia centers of endemism, and $P$. humboldti, endemic to the Inambari and western portion of the Napo center. Haffer (1974 p. 215) considered these taxa conspecific because of intermediate specimens in the region of the Rio Madeira.

A phylogenetic hypothesis (15 steps; consistency index $=0.933$ ) for the second species-group of Pteroglossus is presented in Figure 4 and is based on the characterstate data of Table 4 . The bitorquatus species-group is composed of six taxa, traditionally divided into two biological species (Haffer, 1974). The first consists of three forms often united under the name $P$. bitorquatus: reichenowi of the Rondonia center, sturmii of the Pará center, and bitorquatus of the Belém center. Although they form a monophyletic group, we were unable to resolve the interrelationships of these three forms, and for convenience of discus- 

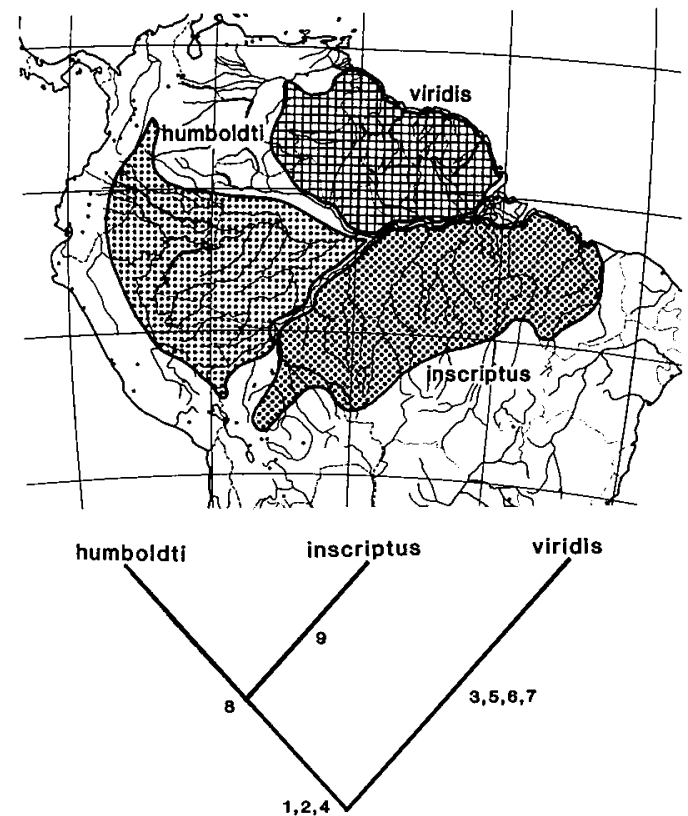

Fig. 3. Distributions and a phylogenetic hypothesis for the differentiated taxa of Pteroglossus viridis speciesgroup. Other species in the genus and other genera of toucans were used as outgroups and the root for the tree. A tree of nine steps (consistency index $=1.00$ ) was produced using nine ordered characters (Table 3 ). Distributions are after Haffer (1974 fig. 16.12 and p. 216).

sion they will simply be called "bitorquatus." The sister-group of "bitorquatus" consists of three differentiated taxa. One of these forms, $P$. azara, is narrowly distributed in

TABLE 3. Character-state data for the Pteroglossus viridis species-group. Characters and character-states are defined as follows. 1) One or more colored bands on yellow belly: $0=$ present, $1=$ absent; 2 ) female throat color: $0=$ black, $1=$ brown; 3 ) female crown color: $0=$ blackish brown, $1=$ chestnut; 4) red postocular spot on facial skin: $0=$ absent, $1=$ present; 5) black culmen stripe: $0=$ present, $1=$ absent; 6) bill largely red at base: $0=$ absent, $1=$ present; 7) upper mandible with dark brown wedge along lower edge: $0=$ absent, $I=$ present; 8) upper mandible with incised vertical striations: $0=$ absent, $1=$ present; 9) lower mandible: $0=$ black, $1=$ extensively yellow with black incised serrations on tomium.

\begin{tabular}{lccccccccc}
\hline & \multicolumn{11}{c}{ Characters } \\
\cline { 2 - 10 } \multicolumn{1}{c}{ Taxon } & 1 & 2 & 3 & 4 & 5 & 6 & 7 & 8 & 9 \\
\hline Outgroup & 0 & 0 & 0 & 0 & 0 & 0 & 0 & 0 & 0 \\
$P$. humboldti & 1 & 1 & 0 & 1 & 0 & 0 & 0 & 1 & 0 \\
$P$. viridis & 1 & 1 & 1 & 1 & 1 & 1 & 1 & 0 & 0 \\
$P$. inscriptus & 1 & 1 & 0 & 1 & 0 & 0 & 0 & 1 & 1 \\
\hline
\end{tabular}
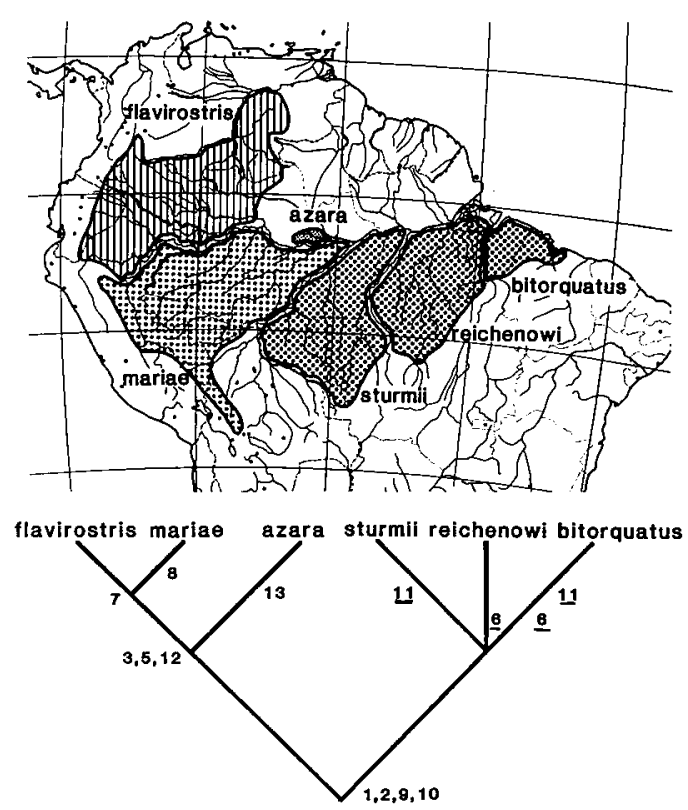

FIG. 4. Distributions and a phylogenetic hypothesis for the differentiated taxa of Pteroglossus bitorquatus species-group. Other species in the genus and other genera of toucans were used as outgroups and the root for the tree. A tree of 15 steps (consistency index = 0.933 ) was produced using 14 ordered characters (Table 4). Distributions are after Haffer (1974 fig. 16.14 and p. 220). Each of the two equally parsimonious trees requires a parallelism in either character 6 or 11 (both of these possibilities are shown on the tree, but the tree length is based on the calculation for either tree).

the Imerí center of endemism. Its sistertaxon, in turn, consists of $P$. flavirostris of the Napo center and $P$. mariae of the Inambari center, which are united on the basis of a single character (brown on the lower mandible). Some hybridization may occur between flavirostris and mariae and between azara and mariae (Haffer, 1974); with respect to the latter two species, hybridization would be misleading if used as an indicator of sister-group relationships.

\section{Historical Congruence of Biogeographic Patterns}

The four clades analyzed here exhibit congruence in their biogeographic patterns. The historical interrelationships of areas of endemism, as revealed by phylogenetic analysis of the taxa, are remarkably similar from one clade to the next. There are several exceptions to this general pattern of congruence, and they raise important issues and problems. 
TABLE 4. Character-state data for the Pteroglossus bitorquatus species-group. Characters and character-states are defined as follows. 1) Nostril openings narrow and notch-like: $0=$ absent, $1=$ present; 2) black culmen stripe: $0=$ present, $1=$ absent; 3) upper mandible ivory color: $0=$ absent, $1=$ present; 4) upper mandible entirely yellow-green: $0=$ absent, $1=$ present; 5 ) lower mandible: $0=$ with black, $1=$ entirely without black; 6) lower mandible: $0=$ entirely black, $1=$ black with proximal one-third greenish-white; 7) lower mandible partially red-brown: $0=$ absent, $1=$ present; 9 ) throat color: $0=$ black, $1=$ dark brown; 10) wide red band on upper breast: $0=$ absent, $1=$ present; 11 ) thin yellow band between throat and breast: $0=$ absent, $1=$ present; 12) wide black band immediately posterior to red on breast: $0=$ absent, $1=$ present; 13) blood-red longitudinal stripe on upper mandible: $0=$ absent, $1=$ present; 14) back with bright red anteriorly: $0=$ absent, $1=$ present.

\begin{tabular}{|c|c|c|c|c|c|c|c|c|c|c|c|c|c|c|}
\hline \multirow[b]{2}{*}{ Taxon } & \multicolumn{14}{|c|}{ Characters } \\
\hline & 1 & 2 & 3 & 4 & 5 & 6 & 7 & 8 & 9 & 10 & 11 & 12 & 13 & 14 \\
\hline Outgroup & 0 & 0 & 0 & 0 & 0 & 0 & 0 & 0 & 0 & 0 & 0 & 0 & 0 & 0 \\
\hline P. bitorquatus & 1 & 1 & 0 & 1 & 0 & 1 & 0 & 0 & 1 & 1 & 1 & 0 & 0 & 1 \\
\hline$P$. reichenowi & 1 & 1 & 0 & 1 & 0 & 1 & 0 & 0 & 1 & 1 & 0 & 0 & 0 & 1 \\
\hline$P$. sturmii & 1 & 1 & 0 & 1 & 0 & 0 & 0 & 0 & 1 & 1 & 1 & 0 & 0 & 1 \\
\hline P. mariae & 1 & 1 & 1 & 0 & 1 & 0 & 1 & 1 & 1 & 1 & 0 & 1 & 0 & 0 \\
\hline P. flavirostris & 1 & 1 & 1 & 0 & 1 & 0 & 1 & 0 & 1 & 1 & 0 & 1 & 0 & 0 \\
\hline P. azara & 1 & 1 & 1 & 0 & 1 & 0 & 0 & 0 & 1 & 1 & 0 & 1 & 1 & 0 \\
\hline
\end{tabular}

The genus Pionopsitta exhibits a major biogeographic disjunction across the Andes, with one lineage having differentiated isolates in Central America and the Chocó, and the other lineage having isolates in centers of endemism within the Amazon basin (Fig. 1). That same major dichotomy is also found in Selenidera (Fig. 2). Within the Amazon basin, moreover, both genera show an identical biogeographic pattern with respect to those areas of endemism held in common: Guyanan + (Belém-Pará + (Inambari + Napo)).

Each genus has one biogeographic component not shared with the other. Pionopsitta pyrilia is restricted to northern Colombia, and Selenidera nattereri is endemic to the Imeri and western Pantepui region. The relationships of the taxa found in the Serra do Mar region of southeastern Brazil also differ in the two clades. In Pionopsitta, this species is the sister-taxon to the rest of the clade, whereas in Selenidera the sister-group of the Serra do Mar endemic is found in the Pará + Belém area. These findings imply either dispersal or different ages for some components of the Serra do Mar avifauna.

The two Amazonian lineages of Pteroglossus (Figs. 3 and 4) are also congruent with the biogeographic histories of Selenidera and Pionopsitta. In the viridis speciesgroup (Fig. 3), the Belém-Pará-Rondônia species $(P$. inscriptus) is more closely related to the Inambari-Napo species $(P$. humbold$t i)$ than either is to the Guyanan form ( $P$. viridis); and in the bitorquatus species-group (Fig. 4), the Inambari species ( $P$. mariae) is more closely related to the Napo species $(P$. flavirostris) than either is to the Belém-ParáRondônia isolate ("bitorquatus"). The bitorquatus species-group has a fourth species, $P$. azara, whose distribution in the Imeri center of endemism parallels that of Selenidera nattereri. The historical pattern between these two latter species is congruent, at least given our present ability to resolve relationships within Selenidera.

The biogeographic patterns of the four clades can therefore be generalized by a single historical hypothesis for all the nonunique areas (Fig. 5). The hypothesis specifies the most precise set of area-relationships supported by the phylogenetic patterns, hence southeast Brazil (Serra do Mar) ap-

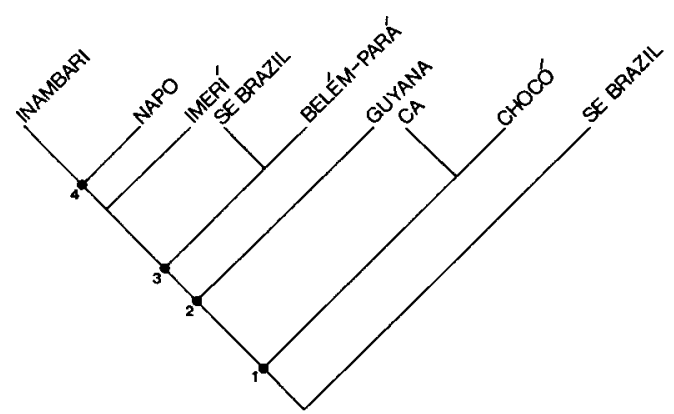

FIG. 5. A general hypothesis for the historical interrelationships of some areas of endemism in tropical America. Vicariance events, indicated by nodes of the tree, are discussed in the text. 
pears as a composite, or biogeographic "hybrid," area having component taxa with different biogeographic histories. Four cladistic events are corroborated by two or more phylogenetic hypotheses (nodes 1-4 of Fig. 5) and thus define a core pattern requiring explanation.

\section{Discussion \\ Speciation and Congruence: $A$ Vicariance Hypothesis}

In a noncomparative approach to the analysis of speciation, differentiation is typically viewed as a series of unique historical events that cannot be understood unless precise details about each of those events are obtained. Comparative analyses that search for congruence in spatial patterns of differentiation among clades permit a different approach to speciation analysis (Cracraft, 1983a, 1986), one that challenges us to seek unifying explanations for shared historical patterns (Platnick and Nelson, 1978; Rosen, 1978).

We propose that the areas of endemism and the corroborated pattern of historical relationships (Fig. 5) arose as a result of a series of vicariance events that segregated a common ancestral biota. Restricting our discussion to the core areas, the first event is postulated to have partitioned this widespread Neotropical biota into Chocó-Central American and Amazon basin components. The next three events subdivided the Amazonian biota: the first isolated the region that was to become the Guyanan center of endemism; the second segregated the southeastern part of the Amazon basin (Belém-Pará-Rondônia centers) from the western portion; and the third segregated the western Amazon region into the Napo and Inambari areas. This hypothesis thus proposes a specific sequence of relative ages for the vicariance events, the endemic taxa, and for the areas themselves (Fig. 5).

The vicariance hypothesis proposed here is highly favored over an explanation that invokes long-distance dispersal and isolation of founder populations (peripatric speciation). A peripatric hypothesis would require numerous parallel dispersal events having similar temporal orders within each of the four clades. Neither explanation can be labeled as "simple" since both necessitate detailed conjectures about past events, but the vicariance hypothesis is more broadly explanatory, generalizable, predictive, and requires fewer ad hoc assumptions than a peripatric hypothesis.

The idea that diversification within the moist forest biota was primarily a result of vicariance is not new. Indeed, the best known and most frequently invoked explanation for the diversification of this biotathe refuge hypothesis-postulates a major role for ecological vicariance of forest and nonforest habitats due to alternating wet/ dry climatic events associated with Quaternary glacial cycles (Haffer, 1969; Vuilleumier, 1971; Simpson and Haffer, 1978). Other potential vicariance events, particularly the origin of physiographic barriers (rivers or mountains, for example), were proposed early in this century but lately have been considered relatively unimportant as causes of geographic isolation and speciation in the lowland forest biota (e.g., Haffer, 1979 pp. 115-117, 1981, 1982; Simpson and Haffer, 1978 p. 510), although proponents of the refuge hypothesis may also accept some species-level diversification prior to the Quaternary (e.g., Haffer, 1983 p. 134, 1985 p. 138). We will discuss some general aspects of the refuge hypothesis in the next section; here we describe and compare the possible vicariance events that might have played a role in the origin of the core areas of endemism shown in Figure 5.

In this treatment, we make no prior assumptions regarding the relationship between the observed degree of differentiation and the age of the taxon. Systematic and evolutionary biologists commonly adopt the view that relative age can be estimated as a direct function of the amount of divergence, but this requires an explicit assumption of constant rates of differentiation across all taxa being compared. We know of no empirical reason to accept such an assumption, and indeed to do so would preclude the unbiased use of systematic data to investigate questions about evolutionary rates.

The temporal correlation of geologicalclimatological vicariance events with the historical relationships postulated by general area-cladograms is problematic (see also Rosen [1985] and Cracraft [1986]). Most 
geological data are not sufficiently finegrained in their temporal and spatial scales to be useful for interpreting biogeographic patterns. Many geologic events, such as uplift producing areas of high relief, may take place over such an extended period of time that it is difficult to correlate them with specific cladogenetic events, which may occur on relatively more rapid time-scales. Finally, paleoecological data are often incomplete temporally and spatially and thus are usually inadequate to specify the location and age of postulated ecological barriers.

Central America-Chocó/Amazonia Vicariance Event (Fig. 5: Node 1). - Two distinct hypotheses have been proposed to explain the trans-/cis-Andean disjunction between Chocó-Central American taxa and their close relatives in Amazonia. Long ago, Chapman (1917 pp. 89, 109-110) suggested that many of the Chocó endemics were isolated ". . . from upper Amazonia before the Andes had acquired a sufficient altitude effectively to separate, as they do now, the Tropical Zones at their eastern and western bases." This endemic fauna, according to Chapman, was then "... cut off from that of upper Amazonia by the Andean uplift." Emsley (1965) also explained a trans-/cisAndean distributional pattern within $\mathrm{Heli}$ conius butterflies in terms of orogenic events in the northern Andes.

The second hypothesis proposes that the disjunction of these trans-/cis-Andean biotas was entirely or predominately ecological and of relatively recent origin. Haffer (1967a, $1967 b, 1969,1975)$ postulated that interchange of the forest biota took place around the northern end of the Colombian Andes (across low passes) during Quaternary glacial cycles when sea level was lower and, presumably, climates were more humid. With the advent of interglacial periods, sea levels rose, and the development of arid environments along the northern coast of $\mathrm{Co}$ lombia and Venezuela partitioned the moist forest biota from east to west.

The hypothesis that trans-/cis-Andean vicariance patterns resulted from physiographic changes has been largely rejected by contemporary biologists, whereas the refuge hypothesis has been extensively promoted and accepted (see next section). Proponents of the latter hypothesis, while generally dis- counting Andean uplift as a potentially significant vicariance event (Haffer, $1967 \mathrm{~b}$ p. 25, 1974 pp. $174-175,1975$ p. 71,1979 p. 115), have provided little counterevidence and, instead, have sometimes treated the hypothesis of speciation in isolated Quaternary refuges as an established fact (e.g., Haffer, $1967 b$ p. 24, 1975 p. 71 ).

Evidence for either hypothesis is circumstantial at best. Geological arguments for or against the role of physiographic vicariance events have all been formulated outside the interpretive framework of plate tectonics. Recent hypotheses about the paleogeographic history of northwestern South America and southern Central America (Malfait and Dinkelman, 1972; Pindell and Dewey, 1982; Burke et al., 1984; Duncan and Hargraves, 1984; Dengo, 1985; Smith, 1985) have identified a number of alternative mechanisms, from uplift of mountains to marine transgressions, that could have separated eastern and western forest biotas at various times during the Cenozoic. The Cordillera Occidental of Colombia, essentially all of the Chocó region, and southern Panama are composed of oceanic (not continental) crust that was accreted to the South American margin (Case et al., 1971, 1984; Case, 1974; Burke et al., 1984; Dengo, 1985). In this area, the Chucunaque Basin of eastern Panama, the Urabá Basin of northern Colombia, and the Atrato-San Juan Basin of western Colombia (the "Bolivar geosyncline") accumulated from 3,000 $\mathrm{m}$ (in the north) to as much as $10,000 \mathrm{~m}$ (in the south) of predominately marine volcaniclastic sediments during the Tertiary (Case et al., 1971; Case, 1974; Dengo, 1985), thus implying the presence of volcanic arcs in eastern Panama and oceanic-derived uplands in western Colombia (Cordillera Occidental, Serrania de Baudó) that would have supported an ancestral Chocó biota for most of the Cenozoic.

In northwestern South America, mountain building has taken place virtually throughout the Cenozoic. Due to interplate compressional stresses, the Cordillera Occidental was elevated as much as $5,000 \mathrm{~m}$ in the middle Eocene (ca. $45 \mathrm{MY}$ ago) and the Sierra de Perijá underwent its initial uplift in the late Oligocene (ca. $25 \mathrm{MY}$ ago) and was apparently raised $3,000-4,000 \mathrm{~m}$ 
(Kellogg, 1984 pp. 244-245; see also summaries of earlier literature by Van der Hammen [1961], Haffer [1970b, 1974], and Simpson [1975, 1979]).

Because substantial tectonic complexity has characterized the northern Andes throughout the Cenozoic (Irving, 1975), numerous physiographic barriers could have arisen to produce vicariance of the forest biota. Unfortunately, as a consequence of this complexity, it may be impossible to specify any particular event as being especially important biogeographically. Certainly, uplift of the Sierra de Perijá and the Eastern Cordillera-Merida Andes beginning in the late Oligocene-Miocene (Irving, 1975; Macellari, 1984) could have provided, at some point in time, a barrier to many elements of the lowland forest biota. Significantly, these major physiographic features were in place prior to the Quaternary.

There can be little doubt that Quaternary climatic cycles influenced the spatial patterns of different plant associations (Van der Hammen, 1974), and such changes may have been important in the Choco-Amazon basin disjunction. Haffer's (1967b pp. 5-8) hypothesis of cycles of interchange between the Chocó and Amazonia during the Quaternary is based in part on the assumptions that the Tertiary Colombian Andes were "rather low mountain ranges" and that they were uplifted primarily in the Pleistocene (1967b pp. 5-6), thus providing the first emergent lowlands to become forested. This hypothesis is not entirely consistent with the more recent geological data cited above. The latter suggest that if the Chocó and Amazonian biotas were interconnected during the Quaternary, then faunal interchange may have been possible only through very narrow, relatively low-lying portals in the Venezuelan Andes and, thus, was more restricted than previously supposed.

Intra-Amazonia Vicariance Events (Fig. 5: Nodes 2-4). - We confine this discussion to alternative hypotheses that explain the historical interrelationships of the four major areas of endemism described earlier: Guyana, Belém-Pará, Napo, and Inambari (Fig. 5). Without question, the predominant explanation for the origin of areas of endemism within the Amazon basin has been the refuge hypothesis (Haffer, 1969, 1974,
1977, 1979; Simpson and Haffer, 1978; Vuilleumier, 1971; see also Prance [1982a]); thus, areas of endemism are considered manifestations of Quaternary forest refuges, within which differentiation has resulted from ecological vicariance of widespread, ancestral forest habitats. Despite disclaimers that not all Amazonian species arose in the Pleistocene, proponents of the refuge hypothesis have generally criticized alternative explanations that postulate pre-Quaternary vicariance within the Amazonian biota. The most important alternative hypothesis regarding a mechanism of vicariance has been the origin and development of broad river valleys or epicontinental marine transgressions. Distributions of many species of plants and animals within Amazonia are frequently bounded by river systems (e.g., Haffer, 1978 p. 71 ; Simpson and Haffer, 1978 p. 510). The Guyana area of endemism, for example, is bounded on the south and southwest by the Amazon and the Rio Negro and by the delta of the Orinoco to the north; the Belém-Pará (and Rondônia) areas are bordered by the Tocantins, Tapajós, and Madeira-Beni rivers; and the Inambari and Napo areas are separated by the Amazon (Solimões) and the Marañón (Haffer, 1974; Cracraft, 1985).

A number of arguments have been invoked against the role of major river systems as agents of vicariance (Haffer, 1974 pp. $102-108,1978$ pp. $69-71,1979$ p. 115 , 1982 pp. 8-9, 1985 p. 137; Simpson and Haffer, 1978 p. 510). Chief among these is the observation that some closely related taxa hybridize in the region of the headwaters, where the river barrier is much narrower. Yet, even though hybridization is observed in some cases, this does not preclude the rivers having been the original basis for vicariance for these taxa or for those that do not hybridize; rivers are dynamic entities and changes in their spatial history may allow populations to come into contact and, possibly, hybridize. A second argument is that competition from those close relatives (or other species), and not riverine barriers, is responsible for maintaining geographic isolation (see especially Haffer [1978 p. 70]). This argument is ad hoc and virtually incapable of empirical assessment inasmuch as any test would necessitate his- 
torical data that cannot be recovered. The hypothesis also requires that allopatry can be maintained by a process that can only take place when populations are in contact. The argument, moreover, does not speak to the role of rivers as mechanisms of vicariance, even given the existence of competition subsequent to differentiation.

A final argument against the importance of riverine vicariance is geological. It claims that the Amazonian lowlands have been relatively stable physiographically for a very long time and that the present river systems are relatively young (Quaternary), primarily because the Andes consisted only of intermittent, low-lying ranges until the PlioPleistocene orogeny (Haffer, 1974 pp. 128130,1979 p. 115,1985 p. 137). The time of the establishment of the major rivers of the Amazon basin is unknown. Even if Quaternary in age, they might still have played a major role in subdividing forest biotas. In fact, however, many of these rivers, especially the larger, well established drainage systems, may be substantially older than the Quaternary. Not only have the Brazilian and Guyanan shields undergone uplift throughout the Cenozoic, the Andes have also consisted of significant uplands since the Late Cretaceous (James, 1971; Zeil, 1979). The Late Miocene-Pleistocene orogeny was only the culmination of several previous orogenic events in the Eocene and Oligocene (Zeil, 1979 pp. 154-156). Thus, some major river systems almost certainly have been in existence throughout the Cenozoic. Haffer (1974 pp. 128-129 [and elsewhere]) has discussed the existence of broad epicontinental marine transgressions at different times during the Tertiary and Quaternary and how these undoubtedly fragmented the forest biota. In summary, it seems reasonable to conclude that the physiographic landscape of Amazonia has been sufficiently diverse and dynamic during the Tertiary to have produced vicariance within the forest biota.

The above discussion is not an argument against ecological vicariance as a result of Quaternary climatic events (i.e., the refuge hypothesis). We stress instead the need to consider pre-Quaternary paleogeographic and paleoclimatic changes as also being potentially important causal agents in promoting allopatry and differentiation within the Neotropical biota. Unfortunately, present geoclimatic and geomorphological data cannot be used to produce a geological areacladogram that can be tested by the biological data.

\section{The Refuge Hypothesis}

Considerable data exist to document extensive habitat change within the South American biota as a result of Quaternary climatic cycles (Haffer, 1974, 1979; Simpson and Haffer, 1978; Prance, 1982a, $1982 b$ ), but that evidence is still inadequate to corroborate the refuge hypothesis and is likely to remain so because of the difficulty of recovering a palynological and paleontological record of sufficient spatial and temporal scale. Thus, acceptance of the refuge hypothesis must necessarily rely upon the acceptance of numerous assumptions. Prime among these is the conjecture that most species-level taxa within the Amazonian biota are no older than the Pleistocene. This is a logical consequence and critical component of the refuge hypothesis, yet virtually no evidence has been offered in its support. Recently, some authors have begun to question this assumption. Heyer and Maxson (1982, 1983), for example, propose that immunological distances among species of Amazonian and coastal Brazilian frogs in the genera Leptodactylus and Cycloramphus indicate divergence times as old as the early Cenozoic in some cases (see Roberts and Maxson [1985] for similar results for Australian Pleistocene "refuges"). Weitzman and Weitzman (1982) also question the assumption that species diversity of Amazonian fresh-water fishes is a Quaternary phenomenon. Capparella (1988) has investigated genetic divergence in three species-groups of manakins (Pipridae) having populations on opposite sides of the Amazon River. Based on the genetic-distance/divergence-time calibration of $\mathrm{Gu}$ tierrez et al. (1983), Capparella (1988) postulates that some divergences may have taken place as long as $2.65 \mathrm{MY}$ ago. In fact, transriverine genetic differentiation within a single subspecies (Pipra coronata coronata) indicates a divergence $0.92 \mathrm{MY}$ ago, which is decidedly older than most episodes of forest fragmentation postulated by the 
refuge hypothesis. Given the evidence for potentially earlier vicariance events, as discussed above, exclusive reliance on the refuge hypothesis requires an assumption that only the most recent plausible mechanism of vicariance is responsible for these biogeographic patterns.

The refuge hypothesis remains a viable explanation for the patterns of vicariance documented in this paper, but considerable problems exist with the method by which this model is often applied. In the majority of cases, Quaternary forest refuges are hypothesized to be located at restricted "core areas" of maximal species diversity and on either side of faunal "suture zones," which represent congruent regions of secondary contact (e.g., Haffer, 1974 pp. 143-144, 1981 p. 380,1982 pp. 15-17, 1985). By focusing explicitly on the positions of hypothetical forest refuges, however, investigators apply a center-of-origin model to a biogeographic process that involves both vicariant isolation and secondary expansion. Such investigations place emphasis on the least generalizable aspect of this model: namely, expansion following allopatric isolation. The initial vicariance of a wide-ranging forest biota by some ecological-climatic change should have a generalized effect on the entire biota, whereas the subsequent secondary expansion away from localized refuges is more likely to be influenced by ecological factors that are unique and intrinsic to each species. Core areas and suture zones are both phenomena of this latter, less generalizable aspect of the refuge model. Speculations about the position of hypothesized refuges or the pattern of expansion following vicariant isolation cannot themselves be used to corroborate the refuge hypothesis. It is for this reason, furthermore, that investigations using these methods have been unable to test the parapatric model of differentiation (see next section). By employing a vicariance model, it is possible to identify historical patterns that could have resulted from the generalizable portion of the refuge model: namely, the segregation of the biota by ecological-climatic events. These patterns, in turn, may be supported or refuted by the results of future systematic investigations of additional elements of the biota and then correlated with sequences of pos- tulated vicariance events as revealed by paleoecological data.

\section{The Hypothesis of Parapatric Differentiation}

The large majority of biologists who have attempted to explain diversity within Amazonia have done so using a model of allopatric speciation via vicariance. Within the context of this model, the central unresolved questions remain the precise pattern of area-relationships, their temporal history, and thus the identification of specific vicariance events. A few workers have proposed an alternative hypothesis to explain contiguous areas of endemism. They suggest that such patterns are the result of present-day ecological barriers to gene flow and that diversification within Amazonia is therefore primarily a manifestation of parapatric, not allopatric, processes (Endler, 1982a, 1982b; Benson, 1982; Beven et al., 1984). As an alternative explanation for diversification of tropical forest biotas, the parapatric model has been criticized by various workers (Futuyma and Mayer, 1980; Cracraft, 1982, 1985; Mayr and O'Hara, 1986).

The vicariance and parapatric models can be most easily distinguished by the prediction of historical congruence. The former model makes a specific prediction: historical congruence will be expected among the speciation patterns of taxa sharing areas of endemism. The parapatric model, in contrast, makes no such prediction. Whereas some taxa may exhibit occasionally parallel patterns of geographic variation across a particular gradient of ecological change, an expectation of historical congruence across large spatial scales (i.e., among multiple areas of endemism, whether contiguous or not) is not deducible from any premises of the parapatric model. Consequently, congruence in the historical patterns of differentiation within different clades, such as documented in this paper, is the best possible kind of evidence for preferring a vicariance model as the primary explanation for biotic diversification within the Neotropics. Endler $(1982 a, 1982 b)$ has suggested that clinal gradients of selection, which might produce parapatric differentiation, will also affect the characters used in cladistic analyses, there- 
by convergently producing congruent, hierarchical patterns in systematic characters that are unrelated to true cladistic events. We contend, however, that many postulated derived characters, such as used here, are very unlikely to have arisen and been maintained by parallel directional selection across each of these clades of birds, let alone across other major taxonomic groups (e.g., plants, insects, mammals) that have biogeographic patterns of endemism congruent with those of birds. At present, the available empirical data do not support the parapatric model.

\section{ACKNOWLEDGMENTS}

We thank the authorities of the American Museum of Natural History (New York), Field Museum of Natural History (Chicago, IL), Museum of Comparative Zoology (Harvard University, Cambridge, MA), and the University of Michigan Museum of Zoology for allowing us to examine specimens in their care. We are grateful to J. Fitzpatrick, J. Haffer, J. Van Remsen, R. Zink, and two anonymous reviewers for their comments on a draft of this paper. A. Capparella kindly lent us an advance copy of his paper. One of us (R.O.P.) initiated his research in neotropical biogeography as a Senior Honors Thesis at the Museum of Comparative Zoology, Harvard University, with the encouragement of W. L. Fink and R. A. Paynter, Jr. This research was supported by NSF grant BSR-8520005 (to J.C.).

\section{Literature Cited}

BENSON, W. W. 1982. Alternative models for infrageneric diversification in the humid tropics: Tests with passion vine butterflies, pp. 608-640. In G. T. Prance (ed.), Biological Diversification in the Tropics. Columbia Univ. Press, N.Y.

Beven, S., E. F. ConNer, AND K. Beven. 1984. Avian biogeography in the Amazon basin and the biological model of diversification. J. Biogeogr. 11:383399.

Burke, K., C. Cooper, J. F. Dewey, P. ManN, ANd J. L. Pindell. 1984. Caribbean tectonics and relative plate motions. Geol. Soc. Amer. Mem. 162: 31-63.

Bush, G. L. 1975. Modes of animal speciation. Ann. Rev. Ecol. Syst. 6:339-364.

Capparella, A. P. 1988. Genetic variation in neotropical birds: Implications for the speciation process. In H. Ouellet (ed.), Acta XIX Congressus Internationalis Ornithologici. XIX Internat. Ornithol. Congr., Ottawa, Canada. In press.

CASE, J. E. 1974. Oceanic crust forms basement of eastern Panamá. Bull. Geol. Soc. Amer. 85:645652.

Case, J. E., L. G. Duran S., A. Lopez R., AND W. R. MOORE. 1971. Tectonic investigations in western Colombia and eastern Panamá. Bull. Geol. Soc. Amer. 82:2685-2712.

Case, J. E., T. L. Holcombe, And R. G. Martin. 1984. Map of geologic provinces in the Caribbean region. Geol. Soc. Amer. Mem. 162:1-30.

Chapman, F. M. 1917. The distribution of bird-life in Colombia; A contribution to a biological survey of South America. Bull. Amer. Mus. Nat. Hist. 36: 1-729.

CRACRAFT, J. 1982. Geographic differentiation, cladistics, and vicariance biogeography: Reconstructing the tempo and mode of evolution. Amer. Zool. 22:411-424.

- 1983a. Species concepts and speciation analysis. Curr. Ornithol. 1:159-187.

. $1983 b$. Cladistic analysis and vicariance biogeography. Amer. Sci. 71:273-281.

1984. The terminology of allopatric speciation. Syst. Zool. 33:115-116.

- 1985. Historical biogeography and patterns of differentiation within the South American avifauna: Areas of endemism. Ornithol. Monogr. 36: 49-84.

2 1986. Origin and evolution of continental biotas: Speciation and historical congruence within the Australian avifauna. Evolution 40:977-996.

1987. Species concepts and the ontology of evolution. Biol. Phil. 2:329-346.

Cronquist, A. 1978. Once again, what is a species? Beltsville Symp. Agric. Res. 2:3-20.

Dengo, G. 1985. Mid America: Tectonic setting for the Pacific margin from southern Mexico to northwestern Colombia, pp. 123-180. In A. E. Nairn, F. G. Stehli, and S. Uyeda (eds.), The Ocean Basins and Margins, Vol. 7A. Plenum, N.Y.

Duncan, R. A., and R. B. Hargraves. 1984. Plate tectonic evolution of the Caribbean region in the mantle reference frame. Geol. Soc. Amer. Mem. 162:81-93.

Eldredge, N., ANd J. Cracraft. 1980. Phylogenetic Patterns and the Evolutionary Process. Columbia Univ. Press, N.Y.

EMSLEY, M. G. 1965. Speciation in Heliconius (Lep., Nymphalidae): Morphology and geographic distribution. Zoologica 50:191-254.

ENDLER, J. 1982a. Problems in distinguishing historical from ecological factors in biogeography. Amer. Zool. 22:441-452.

- 1982b. Pleistocene forest refuges: Fact or fancy?, pp. 641-657. In G. T. Prance (ed.), Biological Diversification in the Tropics. Columbia Univ. Press, N.Y.

Forshaw, J. M., AND W. T. COOPER. 1973. Parrots of the World. Lansdowne, Melbourne, Australia.

FutuYMa, D. J., AND G. C. MAYER. 1980. Non-allopatric speciation in animals. Syst. Zool. 29:254271.

GutierRez, R. J., R. M. ZiNK, AND S. Y. YANG. 1983. Genic variation, systematic, and biogeographic relationships of some galliform birds. Auk 100:3347.

Gyldenstolpe, N. 1951. The ornithology of the Rio 
Purús region in western Brazil. Arkiv Zool. 2:1320.

HAFFER, J. 1967a. Some allopatric species pairs of birds in northwestern Colombia. Auk 84:343-365. - $1967 \mathrm{~b}$. Speciation in Colombian forest birds west of the Andes. Amer. Mus. Novit. 2294:1-57.

-1969. Speciation in Amazonian forest birds. Science 165:131-137.

- 1970a. Art-Entstehung bei einigen Waldvögeln Amazoniens. J. Ornithol. 111:285-331.

—. 1970b. Geologic-climatic history and zoogeographic significance of the Urabá region in northwestern Colombia. Caldesia (Bogota) 10:603636.

- 1974. Avian Speciation in Tropical South America. Nuttall Ornithological Club, Cambridge, MA.

-1975. Avifauna of northwestern Colombia, South America. Bonn. Zool. Monogr. 7:1-182.

- 1977. Pleistocene speciation in Amazonian birds. Amazoniana 6:161-191.

_. . 1978. Distribution of Amazon forest birds. Bonn. Zool. Beitr. 29:38-78.

- 1979. Quaternary biogeography of tropical lowland South America, pp. 107-140. In W. W. Duellman (ed.), The South American Herpetofauna: Its Origin, Evolution, and Dispersal. Univ. Kansas Mus. Nat. Hist., Lawrence.

-1981. Aspects of neotropical bird speciation during the Cenozoic, pp. 371-394. In G. Nelson and D. E. Rosen (eds.), Vicariance Biogeography: A Critique. Columbia Univ. Press, N.Y.

- 1982. General aspects of the refuge theory, pp. 6-24. In G. T. Prance (ed.), Biological Diversification in the Tropics. Columbia Univ. Press, N.Y.

- 1983. Ergebnisse moderner ornithologischer Forschung im tropischen Amerika. Spixiana (Munich) 9:117-166.

-1985. Avian zoogeography of the neotropical lowlands. Ornithol. Monogr. 36:113-146.

HAFFER, J., AND J. W. FitzPATRICK. 1985. Geographic variation in some Amazonian forest birds. Ornithol. Monogr. 36:147-168.

HeYER, W. R., AND L. R. MAXson. 1982. Distributions, relationships, and zoogeography of lowland frogs. The Leptodactylus complex in South America, with special reference to Amazonia, pp. 375388. In G. T. Prance (ed.), Biological Diversification in the Tropics. Columbia Univ. Press, N.Y.

- 1983. Relationships, zoogeography, and speciation mechanisms of frogs of the genus Cycloramphus (Amphibia, Leptodactylidae). Arq. Zool. (São Paulo) 30:341-373.

IRvING, E. M. 1975. Structural evolution of the northernmost Andes, Colombia. U.S. Geol. Surv. Prof. Pap. 846:1-47.

JAMES, D. E. 1971. Plate tectonic model for the evolution of the Central Andes. Bull. Geol. Soc. Amer. $82: 3325-3346$.

KellogG, J. N. 1984. Cenozoic tectonic history of the Sierra de Perijá, Venezuela-Colombia, and adjacent basins. Geol. Soc. Amer. Mem. 162:239261.

MacellaRI, C. 1984. Late Tertiary tectonic history of the Tachira Depression, southwestern Venezuelan Andes. Geol. Soc. Amer. Mem. 162:333-341.

Maddison, W. P., M. J. Donoghue, ANd D. R. MADDISON. 1984. Outgroup analysis and parsimony. Syst. Zool. 33:83-103.

Malfait, B. T., and M. G. Dinkleman. 1972. Circum-Caribbean tectonic and igneous activity and the evolution of the Caribbean plate. Bull. Geol. Soc. Amer. 83:251-272.

MAYR, E. 1942. Systematics and the Origin of Species. Columbia Univ. Press, N.Y.

- 1963. Animal Species and Evolution. Harvard Univ. Press, Cambridge, MA.

- 1982a. Processes of speciation in animals, pp. 1-19. In C. Barigozzi (ed.), Mechanisms of Speciation. Liss, N.Y.

- $1982 b$. Speciation and macroevolution. Evolution 36:1119-1132.

MAYR, E., AND R. J. O'Hara. 1986. The biogeographic evidence supporting the Pleistocene forest refuge hypothesis. Evolution 40:55-67.

Müller, P. 1973. The Dispersal Centres of Terrestrial Vertebrates in the Neotropical Realm. Junk, The Hague, Neth.

Nelson, G. J., ANd N. I. Platnick. 1981. Systematics and Biogeography: Cladistics and Vicariance. Columbia Univ. Press, N.Y.

Pindell, J., AND J. F. Dewey. 1982. Permo-Triassic reconstruction of western Pangea and the evolution of the Gulf of Mexico/Caribbean region. Tectonics $1: 179-211$.

Platnick, N. I., And G. J. Nelson. 1978. A method of analysis for historical biogeography. Syst. Zool. 27:1-16.

Prance, G. T. 1982a. Biological Diversification in the Tropics. Columbia Univ. Press, N.Y.

- $1982 b$. A review of the phytogeographic evidences for Pleistocene climatic changes in the Neotropics. Ann. Missouri Bot. Gard. 69:594-624.

PRUM, R. O. 1982. Systematics and biogeography of the family Ramphastidae (Aves). Senior Honors Thesis. Harvard Univ., Cambridge, MA.

-1988. Historical relationships among avian forest areas of endemism in the Neotropics. In $\mathrm{H}$. Ouellet (ed.), Acta XIX Congressus Internationalis Ornithologici. XIX Internat. Ornithol. Congr., Ottawa, Canada. In press.

Roberts, J. D., AND L. R. MAXson. 1985. Tertiary speciation models in Australian anurans: Molecular data challenge Pleistocene scenario. Evolution 39: 325-334.

Rosen, D. E. 1978. Vicariant patterns and historical explanation in biogeography. Syst. Zool. 27:159188.

- 1985. Geological hierarchies and biogeographic congruence in the Caribbean. Ann. Missouri Bot. Gard. 72:636-659.

Simpson, B. B. 1975. Pleistocene changes in the flora of the high tropical Andes. Paleobiology 1:273-294.

-1979. Quaternary biogeography of the high montane regions of South America, pp. 157-188. In W. E. Duellman (ed.), The South American Herpetofauna: Its Origin, Evolution, and Dispersal. Univ. Kansas Mus. Nat. Hist., Lawrence.

SIMPSON, B. B., AND J. HAFFER. 1978. Speciation pat- 
terns in the Amazonian forest biota. Ann. Rev. Ecol. Syst. 9:497-518.

SMITH, D. L. 1985. Caribbean plate relative motions, pp. 17-48. In F. G. Stehli and S. D. Webb (eds.), The Great American Biotic Interchange. Plenum, N.Y.

SwofFord, D. L. 1985. PAUP, Phylogenetic Analysis Using Parsimony, Version 2.4, Program Manual. Illinois Nat. Hist. Surv. Champaign.

VAN DER HAMmen, T. 1961. Late Cretaceous and Tertiary stratigraphy and tectogenesis of the Colombian Andes. Geol. Mijnbouw 40:181-188.

1974. The Pleistocene changes of vegetation and climate in tropical South America. J. Biogeogr. $1: 3-26$.

Vuilleumier, B. S. 1971. Pleistocene changes in the fauna and flora of South America. Science 173:771780 .
Weitzman, S. H., and M. Weitzman. 1982. Biogeography and evolutionary diversification in neotropical freshwater fishes, with comments on the refuge theory, pp. 403-422. In G. T. Prance (ed.), Biological Diversification in the Tropics. Columbia Univ. Press, N.Y.

WILEY, E. O. 1981. Phylogenetics: The Theory and Practice of Phylogenetic Systematics. Wiley, N.Y.

Wiley, E., aNd R. L. MAYDEN. 1985. Species and speciation in phylogenetic systematics, with examples from the North American fish fauna. Ann. Missouri Bot. Gard. 72:596-635.

ZeIL, W. 1979. The Andes. Gebrüder Borntraeger, Berlin, W. Ger.

Corresponding Editor: J. A. Endler 